\title{
Uma nova espécie de Charidotis Boheman, de Córdoba, Argentina (Coleoptera, Chrysomelidae, Cassidinae) ${ }^{1}$
}

\author{
Zundir José Buzzi ${ }^{2}$
}

\author{
ABSTRACT. A new species of Charidotis Boheman from Córdoba, Argentina \\ (Coleoptera, Chrysomelidae, Cassidinae). Charidotis trifasciata sp.n. from Córdo- \\ ba, Argentina, is described. \\ KEY WORDS. Coleoptera, Chrysomelidae, Cassidinae, Charidotis, new species
}

BOHEMAN (1855) incluiu no gênero Charidotis Boheman, 1855, 45 espécies. SPAETH (1914) cita 122 espécies e o mesmo autor (1936), ampliou para 150; BLACK WELDER (1946) relacionou 170 espécies. HINCKS (1952) designou Charidotis miniata Boheman, 1855 como a espécie-tipo.

Neste trabalho é descrita uma nova espécie de Charidotis que pertencia à coleção do Sr. Anton Maller, Corupá, Santa Catarina, adquirida pelo Departamento de Zoologia da Universidade Federal do Paraná, pelos idos de 1970.

O holótipo coletado em XI.1957, em Córdoba, Argentina, pelo Sr. Arguello, está depositado na Coleção de Entomologia Pe. Jesus Santiago Moure, do Departamento de Zoologia da Universidade Federal do Paraná (DZUP), Curitiba, Paraná, Brasil.

Todas as medidas são em milímetros.

\section{Charidotis trifasciata sp.n.}

Figs 1-2

Em vista dorsal (Fig. 1), corpo alongado, elíptico, cerca de 1,4 vezes mais longo que sua maior largura $(5,50 \times 3,92)$; em vista lateral (Fig. 2), com forte curvatura dorsal, na metade anterior mais suave e posteriormente, decaindo rapidamente; visto de frente, fortemente convexo na altura do meio dos élitros. Coloração geral amarela; esternos torácicos e abdominais, pretos.

Cabeça sulcada, ao longo do meio, do ápice da fronte ao vértice; dorsalmente, entre as órbitas, com dois tubérculos pouco salientes. Genas com grádulo desde a gula até o vértice, passando próximo à órbita posterior dos olhos. Fronte subtriangular, bastante saliente; na base mais larga que longa; aos lados, entre a fronte e a órbita, com forte sulco, da base da mandíbula até próximo aos alvéolos antenais,

1) Contribuição número 1031 do Departamento de Zoologia, Universidade Federal do Paraná.

2) Departamento de Zoologia, Universidade Federal do Paraná. Caixa Postal 19020, 81531-990 Curitiba, Paraná, Brasil.

E-mail: zbuzzi@bio.ufpr.br 
aqui um pouco mais alargado. Olhos, pouco enegrecidos, cerca de 1,6 vezes mais longos que sua maior largura $(0,58 \times 0,36)$. Labro, castanho, margem anterior quase reta, cerca de 2,5 vezes mais largo que longo. Antenas ultrapassando os lados do pronoto; os sete antenômeros apicais enegrecidos (o quinto antenômero, pouco) com pilosidade mais densa e forte, levemente achatados, medindo, do primeiro ao último, respectivamente: 0,$32 ; 0,16 ; 0,10 ; 0,20 ; 0,18 ; 0,16 ; 0,16 ; 0,16 ; 0,16 ; 0,18 ; 0,32$; sulco sensorial inconspícuo, encurtado nos antenômeros oito a dez.

Pronoto cerca de 1,6 vezes mais largo que seu comprimeno mediano; superfície microreticulada com pontuação esparsa; na metade posterior do disco com sulco mediano, longitudinal, suave; margem da projeção mediana posterior, castanho-avermelhada, fracamente convexa e aos lados, com fraca impressão; no disco com três manchas, levemente enegrecidas, duas laterais e uma, mais anterior, no meio e em forma de $\mathrm{V}$, com os bordos indefinidos.

Processo prosternal com pontos esparsos, no meio côncavo; anteriormente com fóvea bem desenvolvida e rebordo bem saliente que circunda a cabeça até o vértice.

Escutelo, castanho, subtriangular, cerca de 1,3 vezes mais largo que seu comprimento mediano; margem basal levemente côncava.

Elitros com três faixas longitudinais, castanho-avermelhadas, com bordos pretos; a do meio, ao longo da sutura, comum aos dois élitros, termina próximo ao ápice elitral; aos lados a faixa preta é encurtada posteriormente e corresponde à primeira fileira de pontos formando sulco bastante forte, próximo ao ápice; as duas faixas laterais, pouco mais curtas que a faixa mediana e nos bordos a faixa preta corresponde à quarta e sétima fileira de pontos; os pontos da porção amarela, com fundo preto e os da nona fileira, maiores que os demais mas menores que os pontos que separam a aba do disco.

Metasterno com superfície estriolada transversalmente; com sulco, ao longo do meio, mais aprofundado anteriormente, logo atrás do mesosterno; anteriormente, na altura da cavidade cotilóide mediana e aos lados, na altura do metaepisterno, com pontos bastante fortes.

Pernas amarelas; trocânteres acastanhados. Último esterno abdominal, com faixa posterior, amarela.

Discussão. Charidotis trifasciata sp.n. é facilmente reconhecida pelas três faixas longitudinais castanho-avermelhadas de bordos pretos. Distingue-se de Charidotis rubrovittata (Boheman, 1855), por esta possuir no disco do pronoto "...vittis duabus longitudinalibus, approximatis scutelloque dilute sanguineis" e nos élitros "...singulo vitta longitudinali, sat lata, inaequali, dilute sanguinea, ante apicem desinente, lineolis duabus flavis, una ante et altera pone medium notata..." (BOHEMAN 1855). 


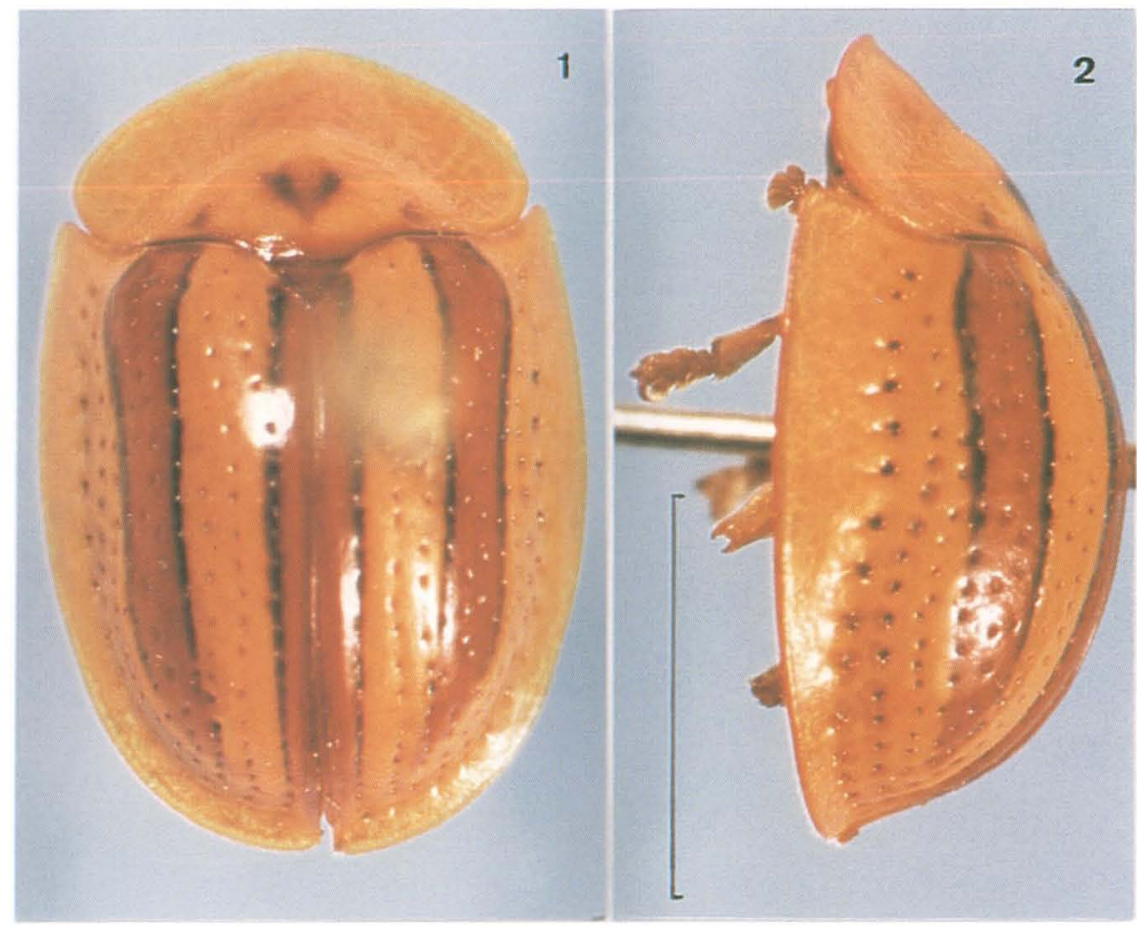

Figs 1-2. Charidotis trifasciata sp.n., holótipo. (1) Vista dorsal; (2) vista lateral. Escala = $2,71 \mathrm{~mm}$.

\section{REFERÊNCIAS BIBLIOGRÁFICAS}

BLACKWELDER, R.E. 1946. Checklist of the coleopterous insects of Mexico, Central America. The West Indies and south America. Bull. U.S. Nat. Mus. 185 (4): 551-763.

BoHEMAN, C. 1855. Monographia cassididarum. Tomus tertius. Holmiae, 543p. HINCKS, W.D. 1952. The genera of the Cassidinae (Coleoptera: Chrysomelidae).

Trans. R. ent. Soc. Lond. 103 (10): 327-358.

Spaeth, F. 1914. Coleopterorum Catalogus 62; Chrysomelidae: Cassidinae. Berlin, W. Junk, 182p.

Spaeth, F. 1936. Bestimmungstabelle der Gattung Charidotis (Col., Chrys., Cassid.). Sborn. Ent. Odd. Nár. Mus. Praze 14: 66-99. 